\title{
Etnicidad e identidad nacional en las políticas del sacerdocio posexílico: Una relectura socio-antropológica de Nehemías 3 y 4
} Etnia e identidade nacional nas políticas
do sacerdócio pós-exílico:
Uma releitura socioantropológica de Neemias 3 e 4
Ethnicity and National Identity in
Post-Exilic Priesthood Policies: A Socio-Anthropological
Re-reading of Nehemiah 3 and 4

\section{Resumen}

En este artículo se analiza el interés que el sacerdocio del segundo templo tuvo por constituir una identidad nacional fundada en la etnicidad, dinámica común en las sociedades pre modernas, según Anthony D. Smith, por lo que usó la historiografía para homogeneizar el pasado y oficializar institucionalmente el acontecimiento de la reconstrucción de los muros de Jerusalén como símbolo de su cultura, quedando registrado en Nehemías 3 y 4. Desde una lectura socio-antropológica de Nehemías 3 y 4 se identifican tres aspectos de un notorio nacionalismo étnico: Jerusalén y su territorialidad étnica, la configuración histórica de las élites a través del uso de las genealogías y el aporte a la construcción simbólica de lo nacional-hermanos en oposición con lo extranjero-enemigos.

Palabras claves: etnicidad, sacerdocio, nacionalismo étnico, Jerusalén, identidad nacional, Yehud.

\section{Resumo}

Neste artigo se analisa o interesse que o sacerdócio do segundo templo teve por constituir uma identidade nacional fundada na etnia, dinâmica comum nas sociedades pré-modernas segundo Anthony D. Smith, por isso usou a historiografia para homogeneizar o passado e oficializar institucionalmente o acontecimento da reconstrução dos muros de Jerusalém como um

${ }^{1}$ Profesor de Teología y Antiguo Testamento en el Seminario Sudamericano - Semisud, Licenciado en Ciencias de la Religión, Master en Sagrada Escritura, Master en Antropología. 
símbolo de sua cultura, deixando registrado em Neemias 3 e 4 . Desde uma leitura socioantropológica de Neemias 3 e 4 identificam-se três aspectos de um notório nacionalismo étnico: Jerusalém e sua territorialidade étnica, a configuração histórica das elites através do uso das genealogias e o aporte para a construção simbólica do nacional-irmãos em oposição com o estrangeiro-inimigos.

Palavras-chaves: Etnia, sacerdócio, nacionalismo étnico, Jerusalém, identidade nacional, Yehud.

\begin{abstract}
This paper analyzes the interest that the priesthood of the second temple had for constituting a national identity based on ethnicity, a common dynamic in pre-modern societies, according to Anthony D. Smith, for which he used historiography to homogenize the past and institutionally officialize the event of the reconstruction of the walls of Jerusalem as a symbol of their culture, as documented in Nehemiah 3 and 4.

From a socio-anthropological reading of Nehemiah 3 and 4, three aspects of a notorious ethnic nationalism are identified: Jerusalem and its ethnic territoriality, the historical configuration of the elites through the use of genealogies and the contribution to the symbolic construction of the national-brothers in opposition to the foreign-enemies.
\end{abstract}

Keywords: ethnicity, priesthood, ethnic nationalism, Jerusalem, national identity, Yehud.

\title{
Introducción
}

Una tarde fui a visitar algunos lugares emblemáticos de la historia oficial de Ecuador. Llegué a la casa de Manuela Sáenz, considerada heroína ecuatoriana de la independencia, además relacionada sentimentalmente con el gran libertador Simón Bolívar. Me llamó la atención que desde uno de los balcones se podía contemplar la montaña donde se había librado la Batalla de Pichincha, que aseguró la libertad de Ecuador del yugo español.

La calle céntrica de la ciudad donde se ubica la casa, ha servido como ruta cotidiana de comerciantes, campesinos y transeúntes, quienes durante los acontecimientos de la guerra por la independencia, con cierto de tipo de cautelas, seguían cumpliendo sus labores diarias, a pesar de que en las proximidades se perpetraban encuentros sangrientos. Así, la montaña en que luchaban los soldados se convirtió en una especie de escenario para los moradores quienes desde la ciudad observaban las incidencias. Manuela Sáenz lo hizo desde su balcón.

La historia de Ecuador, aquella que oficialmente es contada, dice que el 24 de mayo de 1822 se libró la Batalla de Pichincha cerca de Quito 
y que así se fue asegurando la libertad de la dominación española. El testimonio de este acontecimiento del pasado ha sido difundido a lo largo de casi dos siglos, por parte de las instituciones encargadas de generar y desarrollar la conciencia de identidad nacional en los ciudadanos que se identifican como ecuatorianos.

Sin embargo, los trajines en las calles de Quito, con gente que iba y venía procurando resolver situaciones cotidianas en ese mismo día, no se han registrado en los datos que formulan la historia oficial y por ende la identidad ecuatoriana, aunque también formen parte del pasado. El caso es que, desde vías no científicas, algunas de estas otras experiencias del 24 de mayo se han ido constituyendo en sustratos para formas no oficiales de encuentro con el pasado: las memorias del pueblo; concomitantemente, muchas de estas experiencias han tenido que ser relegadas al olvido.

Sobre la base de lo narrado, quiero postular en este artículo, que la última redacción del libro de Esdras-Nehemías, incluida la narrativa de los capítulos 3 y 4 de Nehemías, corresponde a un ejercicio de construcción identitaria del proyecto teocrático, instaurado por el sacerdocio sadoquita desde la institucionalidad del templo de Jerusalén. La documentación historiográfica que pretendieron redactar los sacerdotes en los capítulos citados, tenía como intención homogeneizar el encuentro de los judíos con el pasado, para avalar su etnicidad como fundamento de la identidad nacional, a través de la demarcación y apropiación de la espacialidad de la ciudad de Jerusalén, la configuración de las élites de Yehud², y la construcción de una conciencia de lo nacional en la oposición binaria nacional/extranjero e incluso hermanos/enemigos.

Usaré postulados de las teorías críticas a la Historia ${ }^{3}$ de F. Nietszche y M. Foucault y a la identidad nacional de A. Smith y Z. Bauman, para aplicarlas a la interpretación de las intenciones del escritor de Esdras-Nehemías. Metodológicamente es posible hacer esta aproximación porque las lógicas de la constitución de una identidad nacional están presentes tanto en las sociedades modernas como en los intereses políticos de los sacerdotes posexílicos; empero soy consciente de que existen algunas distancias conceptuales que considero en mi trabajo para evitar conclusiones forzadas: uno, las teorías mencionadas debaten con el cientificismo de la modernidad occidental, que se fue instaurando como patrón para hacer

\footnotetext{
${ }^{2}$ Usaré el término Yehud cuando me refiera a la provincia bajo la administración del gobierno persa. Usaré Judá, cuando trate sobre las aspiraciones de los pobladores locales de la provincia para reconstruir su nación. Para referirme a los pobladores locales de Yehud que buscan la construcción de una identidad nacional propia, usaré el término judíos, sabiendo que existen algunas limitaciones para su entendimiento como por ejemplo la mención sospechosa de este término en Nehemías 4.12, que parece tratarse de un grupo ajeno.

${ }^{3}$ El uso del término Historia con mayúscula, se realizará en concordancia con la crítica de Nietzsche hacia la Historia como ciencia, disciplina o herramienta cognitiva cuya matriz epistemológica está en el acceso confiable al pasado, brindada por la fiabilidad de los datos, para procurar homogeneizar su relación con la realidad presente de un pueblo. Se usará historia con minúscula cuando me refiera al ejercicio de narrar hechos, situaciones, personajes o relatos sobre el pasado.
} 
Historia en Alemania y Francia durante los siglos XVII-XVIII, es decir que no fueron articuladas para criticar los intereses y métodos de los escritores que construyeron la historia de Israel en el Yehud posexílico, aunque los afanes políticos de las clases gobernantes tienen acercamientos a pesar de ser de tiempos distintos. Dos, en el pensamiento moderno, hacer Historia exige un ejercicio reflexivo desde la visión teleológica fundada en la noción de tiempo lineal, en el Yehud del posexilio, recién se comenzaba a configurar esta noción de historicidad, cuestión que aún se discute; lo que implica entendimientos de la temporalidad compatibles, aunque no plenamente. Y tres, la crítica de las teorías mencionadas no se dirige a una comprensión de la Historia desde cosmovisiones religiosas, como la del sacerdocio sadoquita, más bien a una más afectada por la industrialización y el sistema capitalista, no obstante la teoría de Smith busca llevar estas deliberaciones al estudio de las sociedades no-occidentales con predominante pensamiento étnico-religioso.

\section{Aspectos teóricos sobre Historia e identidad nacional}

La construcción del proyecto nacional en la provincia de Yehud, en los siglos V y IV a. C., demandaba la cimentación de una conciencia de unidad en un pueblo cuyo trajín histórico reciente había dejado un paisaje diverso de etnicidades, religiosidades y entramados socioculturales. La identidad nacional era el proyecto necesario. Pero, ¿a qué se denomina identidad nacional?

Definitivamente la teorización política del concepto nación y nacionalidad está circunscrita al surgimiento de órdenes civiles modernos, procedentes principalmente de los ideales de la Revolución francesa; sin embargo es posible usar este concepto también para los pueblos pre modernos constituidos por imaginarios colectivos que no comprenden sólo nociones políticas de ciudadanía. Las naciones pre modernas,

se encuentran en la base de la concepción étnica de la nación. Desde esta concepción se pretende crear naciones a partir de concepciones étnicas preexistentes. Smith $(1991,1994)$ señala la diferencia principal entre la concepción civil y la étnica. Más allá de que la primera se formara a partir de una etnia preexistente y dominante, la diferencia radica en que la concepción civil de nación pretende trascender la etnicidad en una comunidad política común con leyes y cultura comunes para todos, mientras que la étnica lo que pretende es reivindicar el vínculo étnico (HOYOS DE LOS RÍOS, 2000: p. 63).

Este último sería el caso de la propuesta de articulación nacional del sacerdocio en Yehud posexílico.

Entonces, la identidad nacional en pueblos como el judío del posexilio sería el proyecto que tuvieron las élites hegemónicas encargadas del go- 
bierno, para afianzar la vinculación social que garantice la subjetivación ${ }^{4}$, o proceso de constitución del sujeto, de los individuos que formaban parte de la nación, en función de la aceptación de las marcas sobre todo étnicas que los identificaban como pertenecientes al pueblo, porque "la búsqueda de la identidad es la lucha constante por detener el flujo, por solidificar lo fluido, por dar forma a lo informe" (BAUMAN, 2013: p. 85). La procuración de la identidad nacional establece un sentido de pertenencia, da una idea de seguridad basada en la homogeneidad. Así, en sociedades como Yehud, aquel quien no se subjetiva bajo el molde identitario se convierte en riesgo o peligro para el plan total de la comunidad identificada.

Pero, según Bauman, "la idea de una identidad nacional ni se gesta ni se incuba en la experiencia humana de forma natural, ni emerge de la experiencia como un hecho vital evidente por sí mismo." (ALSINA Y MEDINA, 2006: pp. 136-137); sino es una construcción social fundada en las normativas que el Estado y sus organismos hegemónicos han determinado, y "tiene por objetivo el derecho de monopolio para trazar el límite entre el 'nosotros' y el 'ellos' (p. 53)." (BAUMAN citado por ESTRADA, 2005: p. 299)

Los mecanismos para lograr que la identidad nacional se adopte como proyecto común están vinculados con el ejercicio del saber, cuestión ampliamente trabajada por M. Foucault. Una de las principales vías es el oficio del historiador. F. Nietzsche afirmó que éste está estrechamente ligado con la construcción de la idea de nación, por ende con la formulación de la identidad nacional. Porque la Historia "usa el pasado como instrumento para la vida" (NIETZSCHE, 2009: p. 330), es decir que el múltiple acceso posible al pasado se homogeneiza cuando se naturaliza la idea de que existe una única vía para llegar a él: la Historia, construida en el recuerdo monumental o la idealización del pasado circunscrito en los grandes acontecimientos o personajes, y en la conservación y veneración de lo anticuario o la idea de que el pasado no sirve para otra cosa sino sólo para poseerlo y constituirlo como un acervo útil para configurar la vida presente, lo guardado del pasado es lo que realmente sirve, mientras que lo cambiante y dinámico no tiene mayor valor.

Entonces, dice Nietzsche (2009) que "la Historia pertenece, sobre todo, al que quiere actuar, al poderoso, a aquel que mantiene una gran

\footnotetext{
${ }^{4}$ Propuesta de L. Althusser (1976) quien sostiene que la ideología configura la realidad, generando un campo de subjetividad para que el individuo sea interpelado y se convierta en sujeto: "el individuo es interpelado como sujeto (libre)' para que se someta libremente a las órdenes del sujeto" (p. 74). Es decir que el individuo no encuentra, ni puede encontrar, otro camino de existencia que no sea la constitución de sujeto. El individuo acepta su determinación de sujeto por una estructura ideológica autónoma

Por eso, el individuo se sabrá sujeto siempre y admitirá su libertad de ser sujeto, aunque siendo sujeto ya no es libre ni podrá serlo, porque está sujeto a la ideología para que sea sujeto, "por lo tanto para que acepte (libremente) su sometimiento, por lo tanto para que 'realice solo' los gestos y actos de su sometimiento. No hay sujetos sino por su sometimiento y para su sometimiento. Por eso 'marchan solos"' (p. 74).
} 
lucha y necesita modelos, maestros o consuelo" (p. 336), porque lo grande que ha trascendido o el caudal que se ha guardado no pertenece a otro sino al dominante. La Historia es fuente para la construcción de la identidad nacional porque vuelve al pasado en único e imitable.

En el análisis de los capítulos 3 y 4 de Nehemías, pretendo identificar cómo el historiador tuvo, justamente, esta pretensión de aportar a la construcción identitaria nacional, posicionándose en la idea de una unificación de las marcas que los sujetos debían alcanzar, en relación con un pasado que también ha sido unificado, del cual, de manera intencional, hay un gran contenido que fue sometido al olvido, mientras que lo útil fue monumentalizado, sobrevaluado y difundido. Esto debido a que "los historiadores buscan en la medida de lo posible borrar lo que puede traicionar, en su saber, el lugar desde el cual miran, el momento en el que están, el partido que toman." (FOUCAULT, 2003: p. 7) para que así favorezcan a la constitución del sujeto imaginado por el proyecto de identidad nacional, quien como individuo "no sabe quién es, ni qué nombre debe llevar", entonces, "el historiador le ofrece identidades de recambio, aparentemente mejor individualizadas y más reales que la suya" (FOUCAULT, 2003: p. 9).

\section{Aspectos históricos y literarios de Esdras-Nehemías}

Para desarrollar la tesis planteada, voy a argumentar que la configuración identitaria basada en la etnicidad, como proyecto de las élites gobernantes en Yehud, distinguible en la sección del libro de Nehemías que estoy analizando, fue un interés preferente del último redactor(es) o compilador(es) de la obra completa Crónicas-Esdras-Nehemías. No detallaré sobre las aproximaciones y debates contemporáneos acerca de la autoría de Esdras-Nehemías, aunque sí comparto la posición de estudios reputados que distinguen a los autores de Esdras-Nehemías con el de Crónicas (JAPHET, 1993, WILLIAMSON, 1982, KNOPPERS, 2004). También considero que existen suficientes evidencias para decir que, en su forma final "no puede negarse la continuidad entre Crónicas y Esdras-Nehemías" (MENCHÉN, 1995: p. 13), es decir que hubo un esfuerzo editorial para vincular a dos o más obras con trabajos redaccionales dispares, para que, en su conjunto, brinden sostén histórico al afán político-religioso de la corriente ideológica dominante. Knoppers (2005) concluye "que estamos tratando con más de dos complejos literarios que de alguna manera han sido agrupados arbitrariamente ${ }^{5 \prime \prime}$ (p. 72; traducción nuestra), y, cada vez más existe el convencimiento de que no fue un historiador o un cronista el encargado; sino una entidad institucionalizada con un pensamiento cuyo andamiaje se afinó en las propensiones de sus representantes

\footnotetext{
5 "to be dealing with more than two literary complexes that have somehow been arbitrarily thrown together".
} 
por alcanzar el establecimiento y desarrollo de un proyecto nacional en la histórica provincia de Yehud. Así, "es posible postular una escuela cuyos énfasis coinciden con estas obras y que sería la responsable de imprimir su teología tanto en 1-2 Crónicas como en Esd-Neh (cf. Japhet)" (ANDIÑA$\mathrm{CH}, 2012$ : p. 233).

La ubicación temporal de la edición última de la obra también es discutida, aunque se piensa que pudo haberse dado entre el final del periodo persa y el inicio del helénico, entre otras cosas por la referencia que Nehemías "hace de Yadúa (Neh 12,11.22), sumo sacerdote en tiempos de Alejandro Magno" (ABADIE, 1998: p. 10). Durante este periodo, se vivió un apogeo de la dominación institucional del templo, ya instaurado por el Imperio persa, siglos atrás. De tal manera que la edición final de Crónicas-Esdras-Nehemías estuvo permeada por la fuerte propaganda ideológica de la élite sacerdotal.

Ya M. Noth había hecho notar que este grupo privilegiado reclamaba legitimidad desde su parentesco con Sadoc, cuestión que podría haber sido trabajada incluso en la cautividad babilónica por familias de sacerdotes, las que, con la política persa que validó su retorno para el proyecto de reinstauración del templo, se constituyeron en una fuerza político-religiosa que ostentaba la autenticidad de su linaje en una lectura apropiadora del pasado. Los sadoquitas eran

un sacerdocio muy cerrado $[\ldots]$ quienes $[\ldots]$ hicieron ascender su origen hasta Aarón, hermano de Moisés, que ocupaba un papel muy destacado en la tradición. Es evidente que existía alguna conexión con los sadoquitas del período de los reyes, pero eran muchas las familias que exteriorizaban esta pretensión [...] la exacta distinción del grupo 'sadoquita' sólo pudo hacerse tras innumerables luchas internas (NOTH, 1966: p. 305).

La relación entre el cronista y esta élite sacerdotal ha sido ampliamente explorada y es casi indudable su correspondencia, también el mismo texto bíblico muestra las pretensiones que los autores de Esdras y Nehemías tienen sobre el protagonismo de los sacerdotes en la reconstrucción del templo y la ciudad, entonces "los autores deben ser localizados entre círculos próximos al templo en un ambiente de escribas ${ }^{6 "}$ (STEINS, 2016: p. 231; traducción nuestra). Es inevitable pensar que la última mano en unir las obras de Crónicas y Esdras-Nehemías también estaba embebida por el proyecto identitario. Estos escribas "defendieron enérgicamente la centralidad de Jerusalén, en el mismo carácter de la identidad israelita" (KNOPPERS, 2005: p. 72; traducción nuestra).

\footnotetext{
6 "os autores devem ser localizados entre círculos próximos ao templo num ambiente de escribas (cf. A proximidade com $1 / 2 \mathrm{Cr}$ )".

7 "who forcefully argued for the centrality of Jerusalem to the very character of Israelite identity".
} 
Entonces, la tradición escrita fue amoldándose a las exigencias del proyecto identitario y constituyéndose, no en una simple propaganda política; sino en el instrumento para dibujar un pasado único, acción fundamental para la cristalización de la nación imaginada por los sadoquitas. Ideológicamente usaron las tradiciones del éxodo asociadas con la reconstrucción histórica nacional del cronista y del probable último redactor de Crónicas-Esdras-Nehemías para su propósito político-religioso, que reconocía como base la etnicidad, por eso, la constitución de esta identidad fue determinando lógicas de vida binarias: puro/impuro, santo/pecador, nacional/extraño. Este orden religioso-teológico "además de garantizar la concentración económica, él producía la dependencia ideológica, la subordinación política y la mantención de la estratificación social. Por él, el templo de Jerusalén se convirtió en un centro económico y político de dominación en Judá" (GALLAZZI, 1996: p. 163).

S. Gallazi (1996) también afirma que la misión o "el trabajo de Esdras, y sobre todo de Nehemías, produjo este proyecto hierocrático que sustituyó el viejo proyecto monárquico/davídico, atendiendo a los intereses de la corte aqueménida y a la teología de los judíos de la diáspora" (p. 163).

Por lo que fue imprescindible usar las memorias de Nehemías como boceto de una historiografía que soporte la institución de la nueva nación israelita, en Yehud, bajo la dominación ideológica de los sadoquitas.

Entonces, la construcción de la identidad nacional fundada en un nacionalismo étnico ${ }^{8}$ no sólo fue un proyecto tardíamente pensado por los sadoquitas; sino que se fue trazando a partir de la constitución de élites gobernantes, en los inicios de la provincia. La configuración de estos grupos de poder implica también la de lo subalterno $y$, consecuentemente, de la hegemonía ideológica (GRAMSCI, 1977). Frente a esto, nos preguntamos, ¿cómo emergió en Yehud la supremacía de ese estrato social privilegiado, étnicamente identificado como judío?, sobre todo si era una provincia subyugada por el Imperio persa.

Según Finkelstein y Silberman (2011), los grupos hegemónicos establecidos en Jerusalén brotaron gracias a los intereses y políticas del mismo imperio dominante. Desde sus investigaciones histórico-arqueológicas postulan:

los reyes persas fomentaron la aparición de una élite local en Yehud debido a la delicada y estratégica situación de la provincia en la frontera con Egipto. Aquella élite leal fue reclutada de entre la comunidad judía del exilio babilónico y estuvo dirigida por dignatarios estrechamente vinculados a la administración persa (p. 315).

\footnotetext{
${ }^{8}$ Concepto usado por A. Smith para explicar la base de la construcción identitaria en sociedades premodernas. En párrafos siguientes se explicará con más amplitud.
} 
Esto nos exige pensar que Yehud era importante para el interés persa, no por su riqueza, ni porque existiera una relevancia propia; sino porque estratégicamente era un territorio que permitía algún control en las relaciones fronterizas con el poderoso y peligroso Imperio egipcio. También podemos argüir que la instauración de las élites jerosolimitanas fue un acto premeditado por los persas, no precisamente por su amabilidad o generosidad con sus subalternos judíos; sino porque convenía para las nuevas políticas de dominación sobre los pueblos conquistados. Porque "los persas otorgaban a los pueblos una cierta autonomía en sus provincias que se relaciona sobre todo con cuestiones culturales" (KESSLER, 2013: p. 202) y, por tanto con cuestiones religiosas, íntimamente ligadas con las étnicas. "La finalidad de esta nueva política es atraer hacia la casa real aqueménida, mediante la lealtad, a los pueblos dominados. El objetivo principal era la recaudación de los impuestos imperiales" (KESSLER, 2013: p. 203).

Entonces, las élites de Yehud cumplían un plan político-económico del Imperio persa, lo que no quiere decir que este plan era completamente ajeno a la restauración de la adoración a la divinidad local, porque, como lo plantea D. Edelman (2005), las evidencias bíblicas y arqueológicas demuestran que tanto la reconstrucción del templo y de las murallas eran "una parte integral de un plan múltiple y no un movimiento aislado para ganar el favor de los locales al reinstalar a su dios" (p. 349; traducción nuestra). Para Edelman (2005) existe la posibilidad de, incluso, conjeturar que las misiones de Zorobabel y Nehemías podrían tratarse de "la misma persona histórica que se ha dividido en dos personas diferentes en la literatura como resultado de la decisión de colocar la reconstrucción del templo casi setenta años antes que la reconstrucción de Jerusalén, por razones ideológicas $^{10 \prime \prime}$ (p. 351; traducción nuestra). Aunque aún debatible, esta hipótesis está asentada en la idea de que fue necesario documentar y difundir claramente que los persas pusieron gobernadores encargados de asuntos políticos, pero que su centro de regencia era la institucionalidad religiosa, por eso había que narrar a Zorobabel llegando primero para construir el templo, y Nehemías después para edificar la ciudad, aunque lo más lógico es que estas obras de construcción se hicieron de manera sincrónica (cf. Edelman).

Pero, ¿qué tipo de religiosidad practicaba esta élite?, recordemos que el yavismo era una expresión religiosa que había calado en distintos estratos de la población israelita, desde los tiempos monárquicos. Existen relatos bíblicos provenientes de la vida del campo que evidencian al ya-

\footnotetext{
9 "an integral part of a multi-pronged plan and not an isolated move to gain the favor of locals by reinstating their god".

10 "Zerubbabel and Nehemiah represent the same historical person who has been split into two different people in the literature as a result of the decision to place the rebuilding of the temple almost seventy years earlier than the rebuilding of Jerusalem, for ideological reasons".
} 
vismo como su espiritualidad preferente; pero también hay textualidades que manifiestan que en la ciudad se estableció una fuerte aspiración por la institucionalización de esta creencia.

Durante el posexilio, los siervos judíos, comisionados por los persas, guardaban un trasfondo religioso que fue animado por las ventajas de las nuevas normativas administrativas del Imperio, así, ellos fueron reconstruyendo el yavismo que en esa época, debido a la fragmentación de la población, había tomado nuevas formas y configurado significados adaptados a la nueva situación sociocultural. "Se trataba principalmente de individuos de alto rango social y económico, familias que se habían resistido a ser asimiladas y que, muy probablemente, se sentían próximas a las ideas deuteronomistas" (FINKELSTEIN Y SILBERMAN, 2011: p. 315).

Por esa razón, fue posible la integración de las espiritualidades provenientes del campo, residentes en Judá, con las de las élites judías procedentes de la cautividad, pero además, los consensos religiosos, también alentaron la idea de una unidad étnica.

Aunque los repatriados eran una minoría en Yehud, su condición religiosa, socioeconómica y política y su concentración en Jerusalén y sus alrededores les daban un poder mucho mayor que el de su número. Es probable también que contaran con el apoyo de la población local, afecta al código legal deuteronómico promulgado un siglo antes (FINKELSTEIN Y SILBERMAN, 2011: pp. 315, 316).

Entonces, la construcción de la identidad nacional, basada en su etnicidad, no fue una excentricidad antojadiza de las élites jerosolimitanas; sino que germinó desde un deseo legítimo por salvaguardar las tradiciones del yavismo, que desde su marco religioso implicaba también la construcción simbólica de un nuevo pueblo, aunque dominado por los persas, diferenciado de ellos por asuntos religiosos, concebidos también como cuestiones étnicas.

Aquí planteo una siguiente pregunta, ¿por qué, a partir del siglo V, las élites de la provincia de Yehud habían comenzado a construir preámbulos de índole étnico a la posterior constitución institucionalizada de la identidad nacional?

Además de lo relatado anteriormente, postulo que la temporalidad señalada, el siglo V a.C., fue epicentro del brote del proyecto de identidad nacional porque las circunstancias que devinieron en la fundación política de la provincia de Yehud, estuvieron marcadas por la necesidad de una distinción étnica en Yehud, afirmación que está acorde con la tesis de Anthony Smith acerca de la concepción étnica de la nación.

A pesar de que la instauración de la provincia y la consecuente formación de una élite gobernante local provenían de los intereses persas, la provincia estaba sometida a la dominación imperial, así que, aunque al 
parecer Esdras y Nehemías tuvieron la urgencia de obedecer las disposiciones de Artajerjes, hubo un sector que engendró una imperiosidad por distinguirse culturalmente de Persia. No es extraño que la propaganda política de Ageo y Zacarías a favor del proyecto de Zorobabel se haya inclinado por la maquinación de un proyecto más nacionalista que se atrevió a postular una cuasi monarquía. En Ageo 2.21-23 se expresa: "Habla a Zorobabel, gobernador de Judá... Yo voy a sacudir los cielos y la tierra. Daré vuelta a los tronos de los reinos, y destruiré el poder de los reinos de las naciones... Aquel día, oráculo de Yahveh Sebaot, te tomaré a ti, Zorobabel, hijo de Salatiel, siervo mío, oráculo de Yahveh, y te pondré como anillo de sello, porque a ti te he elegido..."

Como "los persas toleraban y hasta fomentaban los cultos locales como una manera de asegurar la lealtad de grupos particulares al conjunto del imperio" (FINKELSTEIN Y SILBERMAN, 2011: p. 315), el templo de Jerusalén se constituyó en el lugar para el despliegue de la nueva política tributaria persa, pero a la vez en un espacio desde donde se comenzó a postular la configuración simbólica de la autenticidad de la etnia y la cultura judías, básicamente porque se autorizó el desenvolvimiento libre de la religiosidad yavista y no la persa. Así, más tarde el templo se convertiría en un centro de la normalización y regulación de la etnicidad.

Los relatos de Ageo y Zacarías sobre la construcción y dedicación del templo están embebidos por un deseo de reconocer que la tradición religiosa es un símbolo de la naturalidad de la cultura de un pueblo que, si bien es cierto está subyugado, no ha sido totalmente asimilado por la cultura dominante del Imperio persa. Incluso, el relato de Esdras 6 narra la culminación de la obras del templo con un visible desaire a las autoridades persas mencionadas como Tattenay, y una exaltación de las expresiones culturales cultuales de los judíos, acontecido, según el texto bíblico, al finalizar el sexto año del gobierno de Darío. S. Croatto arguye:

la inmediata celebración de la pascua al comienzo del año siguiente (fines de abril del $515 \ldots$...) no puede dejar de tener resonancias liberacionistas. Llama la atención el hecho de que Zorobabel desaparece súbitamente de las fuentes bíblicas, ni hay más rastros de la dinastía davídica (1994, p. 241).

Probablemente porque la posible intentona independentista fue apabullada por el régimen imperial.

Entonces, escapar de la dominación persa era imposible, lo alcanzable fue la distinción étnica que implicaba también la diferenciación de otros pueblos que habitaban esa tierra. La etnicidad se fortaleció con el desligamiento político de otra provincia con la que Yehud tendría una relación disímil debido a discrepancias provenientes desde tiempos monárquicos: Samaria. 
Geopolíticamente fue instaurada la satrapía quinta de los persas llamada Abar Náhara o Transeufratene, "de la que formaban parte Siria, Palestina, Chipre y al final del periodo la costa de Cilicia. Palestina estaba dividida en circunscripciones territoriales llamadas medinot (plural de mediná), o provincias" (AGUILERA, 2018: p. 16), una de ellas, Samaria. Existe casi un consenso entre los historiadores acerca de que la provincia de Samaria, si no fue anterior a la de Yehud, por lo menos ejerció influencia sobre ésta, de la que existen referencias todavía después de la mitad del siglo. La historiadora M. Aguilera afirma que la acuñación de monedas en Yehud comenzó a realizarse en el siglo IV a.C. por ser una provincia tardíamente constituida.

Kessler discute con los clásicos postulados de Albretch Alt, apoyándose en testimonios epigráficos, sobre la subordinación de Yehud a Samaria. Para Alt, las hostilidades entre estas provincias durante el siglo V se dieron porque Yehud fue inicialmente una subprovincia de Samaria; sin embargo la argumentación al respecto es cuestionable. Aún así, Kessler cree que no es posible entender a Yehud sin la influencia política de Samaria en este siglo. "Políticamente quedan como entidades separadas cuya mutua relación está llena de tensiones. Solo a mediados del siglo V, con la entrada en escena de Nehemías, Judá se aleja políticamente de la sombra de Samaria". (KESSLER, 2013: p. 206). La delimitación geopolítica de Yehud, trajo consigo la distinción étnica entre judíos y samaritanos, lo que aportó a la formulación de un proyecto identitario.

Para Edelman, en el siglo V se establecen los límites de la provincia de Yehud, durante el gobierno de Artajerjes I (465-433 a.C.), bajo el liderazgo de su comisionado Nehemías, quien, además organizó la reconstrucción de la ciudad de Jerusalén (y del templo), aspiración que generó hostilidades por parte de pobladores antiguos de ese territorio, como lo atestigua "la referencia extrabíblica a hijos adultos de Sanbalat, gobernador de Samerina, el "adversario" de Nehemías, en el papiro Elefantina AP 30, fechado 408 BCE $^{11 "}$ (EDELMAN, 2005: p. 209). Edelman sostiene que el trabajo de Nehemías fue cumplir con el interés persa de integrar a esta población al imperio. Pero en esta delimitación, a pesar de que Nehemías no tenía el plan para establecer una identidad étnica o postular la noción de una nación israelita, fue consecuentemente impostergable la distinción político-cultural de Yehud, de las otras provincias, sobre todo de Samaria.

\section{La identidad nacional en el nacionalismo étnico expuesto en las narrativas de Nehemías 3 y 4}

Existen abundantes aportes de los comentaristas sobre el listado de personajes, sus familias y sus lugares de procedencia, además de los sec-

\footnotetext{
${ }^{11}$ the extra-biblical reference to the adult sons of Sinuballit, governor of Samerina, the 'adversary' of Nehemiah, in Elephantine papyrus AP 30, dated 408 BCE".
} 
tores donde trabajaron en la obra de reconstrucción de las murallas, descritas en Nehemías 3, también es copioso el material exegético acerca de la perícopa del capítulo 4 . Por esto procuraré no describir lo que ha sido ampliamente tratado.

Mi interés está en analizar cómo la textualidad de los capítulos 3 y 4 de Nehemías exhibe documentariamente el eje epistemológico que sostiene el entendimiento de las lógicas de vida del pueblo en su momento histórico, en este caso los siglos V y IV a.C., y va configurando a un sujeto, particularmente desde su etnicidad, por ende determinando lo que no es el sujeto, y a partir de esta oposición, constituir la representación de lo que es, debe ser y cómo aparece el mundo y su orden social. Además, cómo se legitima esta imaginación en las apropiaciones cognitivas del pasado que favorecen al asentamiento y asentimiento de una noción clara de lo que hace al judío ser judío, es decir cómo se configura la identidad nacional. Por eso estoy de acuerdo con Finkelstein y Silberman (2011) cuando afirman que

una de las principales funciones de la élite sacerdotal en Jerusalén posterior al exilio - además de la realización de nuevos sacrificios y ritos de purificación - fue la producción continua de literatura y escritos para mantener unida la comunidad y determinar sus normas frente a los pueblos del entorno (p. 318).

En los capítulos 3 y 4 de Nehemías nos encontramos frente a una documentación del acceso que el sacerdocio sadoquita ha hecho a un pasado no muy lejano en la provincia de Yehud, para transmitirlo como fundamento de su proyecto de construcción de una identidad nacional.

Para esta parte de mi análisis, vuelvo a la teorización de A. Smith sobre nacionalismos y etnicidad. Primero, si bien es cierto que nación y nacionalismo son categorías conceptuales constituidas en el pensamiento moderno, pensemos también que "no hay nación consolidada ni nacionalismo exitoso sin la previa existencia de una comunidad étnica" (GAYO, 2001: p. 251), es decir que además de los nacionalismos geopolíticos de la modernidad, ha existido un nacionalismo étnico desplegado en las comunidades étnicas, que son formas sociales predominantes en las sociedades pre-modernas. Así la etnicidad y no el etnocentrismo configuraron el patrón que unificaba las poblaciones de estos pueblos. En segundo lugar, Smith dice que "en términos generales, el etnicismo ha manifestado tres objetivos generales en la antigüedad y en la Edad Media: la restauración territorial, la restauración genealógica y la renovación cultural ${ }^{12 \prime \prime}$ (1988: p. 51; traducción nuestra).

12 "Broadly speaking, ethnicism has manifested three broad aims in antiquity and the Middle Ages: territorial restoration, genealogical restoration and cultural renewal". 
Estos tres aspectos son reconocibles en la narrativa de Nehemías 3 y 4. En el capítulo 3 se manifiesta la pretensión de reconfigurar una territorialidad, no sólo geopolíticamente como fue el interés de Persia al fundar la provincia de Yehud, sino étnicamente. Por otro lado, en ese mismo capítulo se establece una lista de familias que participaron en la obra de reconstrucción de la muralla, relacionada con los padrones símiles de Nehemías 7 y Esdras 2, que buscan identificar orígenes genealógicos. Y además, a partir del 3.33 hasta el capítulo 4 se incluye la narrativa, considerada como memoria, que resalta el valor de la cultura como agente unificador de los pobladores, reconocidos como hermanos, en oposición a aquellos que no forman parte de esta cultura, a quienes se considerarán como extranjeros y hasta enemigos.

Antes de avanzar, fijémonos que los textos del capítulo 3.1-32 y del $3.33-4.17^{13}$ no pertenecen a la misma autoría. El debate actual sobre la paternidad literaria de Nehemías no ha señalado nuevos consensos, aún se habla sobre una muy probable primera escritura de un autor, distinguido por algunos exégetas como el mismo Nehemías, quien a manera de memorias, así reconocido básicamente por el uso de la primera persona en la narrativa, cuenta lo acontecido en Yehud, a mediados del siglo $\mathrm{V}$ a.C., bajo la dominación del rey persa Artajerjes I. Pero estas memorias están intercaladas por inclusiones de otro autor o autores, que no usan la primera, sino la tercera persona y escriben desde una temporalidad posterior a la de las memorias de Nehemías.

De acuerdo con P. Abadie (1998), el relato del capítulo 4 se reconoce como parte de las memorias de Nehemías, mientras que el capítulo 3 como parte de un relato él, que no pertenece a una sola composición paralela a las memorias; sino que "se trata más bien de elementos dispersos, como una pieza de archivo conservada seguramente en el templo (Neh $3)$, reunidos por un editor tardío e integradas en la $\mathrm{MN}^{\prime \prime}$ o memorias de Nehemías (p.8).

\section{Territorialidad y nacionalismo étnico en Nehemías 3.1-32}

Nos centraremos en la sección comprendida por los versículos 3.132 para analizar tres cuestiones respecto a las pretensiones de salvaguardar una territorialidad étnica.

La territorialidad étnica a diferencia de la geopolítica, no está fundada en límites geográficos y fronteras que delimitan políticamente una región; sino en mitos de origen y en la defensa de una conciencia étnica de un pueblo que ha asumido que su identidad se circunscribe en la pertenencia y hasta en una relación social entre el pueblo con la tierra, mejor dicho, su tierra. Smith (1988) afirma que el valor que una comunidad étnica le da al territorio "implica, por un lado, la resistencia primaria a la

${ }^{13}$ En la versión Reina Valera, usada en el ámbito evangélico, la sección va del 3.1-32 y del 4.1-23. 
invasión como defensa de la comunidad y su cultura; y, por otro lado, un movimiento para recuperar el territorio que se cree pertenece a la comunidad $^{14 \prime \prime}$ (p. 51). La amenaza de una conquista significaba la posibilidad de que su identidad se resquebraje por la pérdida del sentido de pertenencia, y peor aún si se trataba de un exilio, porque ser apartado de la tierra denotaba perder la relación social con aquello que se consideraba matriz de la identidad.

Lo primero que podemos destacar es que el autor original del relato de 3.1-32 y el editor final del libro consideraron fundamental historiografiar ${ }^{15}$ sus pretensiones patrióticas en una narrativa sobre la posesión de un territorio, porque era una manera de lograr que el judío se distinga como judío.

El editor se toma la libertad de interrumpir el relato en primera persona o las memorias de Nehemías, para incluir el listado detallado de reconstructores de las murallas de Jerusalén. Provoca esta discontinuidad en el relato justo cuando Nehemías responde a Sambalat, Tobías y Guesem, detractores de su misión, encarándoles que ellos no tienen porqué opinar acerca de una tierra con la que no guardan relación. Nehemías 2.20 dice: "Yo les respondí: - El Dios del cielo coronará nuestros esfuerzos. Nosotros, sus siervos, vamos a empezar los trabajos; a vosotros en cambio, nada os pertenece en Jerusalén; no tenéis en ella derecho alguno, ni nada que os sirva de recuerdo", vemos en el texto que la legalidad de pertenencia a la tierra se justifica en la relación que el pueblo tiene con ella, por eso experiencias subjetivas como el recuerdo o la memoria puede determinar el derecho de territorialidad. No es extraño que esta declaración sirviera como marco óptimo para que el editor último incluyera la lista del capítulo 3.

Pero además de eso, tan sólo el hecho primigenio de pensar que es necesario escribir un relato como éste manifiesta una lógica de pensamiento que concibe a la territorialidad como aspecto fundamental para la existencia de un pueblo, por eso luego las élites pudieron usarlo como instrumento histórico para la asunción de una nacionalidad étnica. Entonces, no se trata sólo de una simple lista; sino de avalar políticamente la relación del pueblo con la tierra, por lo cual el padrón "presenta una serie importante de indicaciones topográficas de Jerusalén en el período postexílico" (PAGÁN, 1992: p. 127).

En segundo lugar, la territorialidad historiografiada en este relato tiene como núcleo a la mítica Jerusalén. El pueblo consentía que el valor etno-simbólico de Jerusalén hacía reconocerla como la tierra, lo que está capitalmente expresado en la narrativa, más que su notabilidad geopolítica o económica.

\footnotetext{
14 "it involves, on the one hand, primary resistance to invasion conceived as a defence of the community and its culture. And, on the other hand, a movement to reacquire lost territory thought to belong to the community".

${ }^{15}$ Entiéndase como narrar y documentar la Historia.
} 
Recordemos que, de acuerdo con 2 Reyes 25.23-25, Gedalías fue puesto como gobernador por el mismo mandato babilónico, en Mispá, lugar relevante para el trabajo político de Jeremías, y también se menciona a Mispá repetidamente en la lista de Nehemías 3, Edelman (2005) afirma que: "Mispá aún era reconocida como la sede provincial, lo que sugiere que la transferencia de esa función a Jerusalén no podría tener lugar hasta que se completaran los muros ${ }^{16 \prime \prime}$ (p. 222, traducción nuestra), entonces, lo más racional sería que los persas reconstruyeran y militarizaran Mispá, como acción estratégica, por ser capital de la provincia y no Jerusalén.

K. Hoglund (1992) ha realizado una investigación histórico-arqueológica sobre la reconstrucción de los muros y llegó a la conclusión de que la intención persa fue erigir una fortaleza militar en Jerusalén para el mejor control político de la región, sin embargo, Edelman (2005) señala que si hubiese sido así, queda irresuelto por qué el rey persa no encargó a Nehemías la edificación de la fortaleza en Mispá. Probablemente porque Mispá era la capital de la provincia, pero Jerusalén poseía un valor etno-simbólico que significó un riesgo para la dominación persa, y un valor para la cohesión étnica de los judíos.

Para Smith, la territorialidad como aspecto de la nacionalidad étnica, tiene un carácter más mítico que físico, es decir que si bien es cierto que había un valor etno-simbólico en reconstruir Jerusalén, había uno aún mayor en historiografiarlo porque así se consolidaba como un elemento cultural fundante, por tres razones: uno, los elementos culturales definen y legitiman la relación entre sectores, grupos dominantes e instituciones con la comunidad, posibilitando una conciencia común, primordialmente en tiempos de crisis; dos, los elementos culturales permiten la distinción entre nosotros y ellos, sobre todo de los extranjeros; tres, estos elementos brindan las oportunidades para dar sentido de continuidad a la nación con las generaciones pasadas (SMITH, 2009: p. 25).

Entonces, Jerusalén y los relatos históricos acerca de ella fueron una insignia para el reconocimiento de la etnicidad y la promoción de la identidad, porque había una alta carga de significados configurados desde la monarquía. La detallada datación de los lugares reconstruidos tiene más valía ideológica que geográfica porque "la localización de numerosos sitios citados en Neh 3... es a veces incierto y discutido" (ABADIE, 1998: p. 52), incluso la inserción de cuestiones históricas como el reniego de los nobles de Teqoa o la mención de los sepulcros de David, son importantes para que el historiador no sólo narre la reconstrucción de las murallas; sino para que reconstruya la centralidad mítica de Jerusalén.

En tercer lugar, el sentido de la reconstrucción que el autor relata, manifiesta una pretensión de apropiación del espacio. Es improbable que

\footnotetext{
16 "Mizpah was still acknowledged as the provincial seat, suggesting that the transfer of that function to Jerusalem could not take place until the walls and administrative complexes within them were completed".
} 
el autor haya relatado la reconstrucción en el orden en que ésta se dio. "La descripción del programa de restauración comienza con la 'puerta de las Ovejas' (v. 1); continúa contraria a las manecillas del reloj; a través de la periferia de la ciudad; y finaliza en las 'puertas de las Ovejas' nuevamente (v. 32)" (PAGÁN, 1992: p. 129); antes bien da la impresión que simbólicamente el autor está usando la narración para legitimar la delimitación del espacio usando a ciertos actores sociales y consecuentemente la apropiación de éste para así tener conciencia de la pertenencia a y de un territorio (RAFFESTIN, 2011), en este caso recurriendo a datos con inexactitudes en la distribución arquitectónica, pero con validaciones etno-simbólicas que permiten el reconocimiento de la territorialidad étnica de Jerusalén.

E. Cortese (2005) encuentra que la serie de puertas nombradas en el relato

parece que son demasiadas para considerarlas como puertas de las murallas. La duda no solo se suscita porque, a excepción de la puerta de los Caballos, las otras no se mencionan en ningún otro texto... En total, según nuestro capítulo, había diez puertas, mientras que en la Jerusalén actual... apenas llegan a siete (p. 803).

Siendo que la ciudad contemporánea tiene una extensión mucho mayor, por ende sus murallas también. Si el orden del avance de la restauración de las murallas no está trazando un itinerario de la restauración de la ciudad, por la inverosimilitud de las puertas citadas, podría existir una razón más etno-simbólica para concebir y documentar este orden.

Edelman (2005) nota que la procedencia de algunas familias constructoras son las poblaciones benjaminitas al norte de Jerusalén, donde se habrían instalado algunos de los que iban llegando desde Mesopotamia, porque durante el exilio babilónico, los asentamientos en lo que sería Yehud, "se concentraron en el territorio tradicionalmente asociado con Benjamín ${ }^{17 \prime \prime}$ (p. 223; traducción nuestra), como Jericó, Gabaón y Mispá. Además, el reporte del capítulo 3 también menciona que los constructores vinieron de poblaciones del sur y del norte. Aún así, los datos no son suficientes para concluir que el autor está informando que la reconstrucción implicó el trabajo conjunto de los judíos asentados en las poblaciones dentro de la delimitación geopolítica oficial de Yehud, tampoco, que se trate de un informe certero sobre la participación de los pobladores de los lugares a donde llegaron los que retornaban. El manejo de los datos sobre los pobladores de Yehud y su participación en la reconstrucción de las murallas no responden a un inventario cabal por parte del escritor y editor,

la decisión de ubicar a los retornados en sitios principalmente dentro de Benjamin ha sido motivada por preocupaciones distintas a un informe preciso de los eventos. Una motivación subyacente puede haber sido el deseo

17 "were concentrated in the territory traditionally associated with Benjamin". 
de afirmar que aquellos en Yehud que habían regresado de Babilonia eran verdaderos herederos del nombre de Israel y representaban a esta entidad en su transformación en una comunidad religiosa en lugar de un reino ${ }^{18}$ (EDELMAN, 2005: p. 225; traducción nuestra).

Por tanto, el autor y editor tuvieron más interés en significar etno-simbólicamente la reedificación de la ciudad, que en retratar estrictamente los trabajos de construcción, para así afinar la conciencia de que la territorialidad étnica de Jerusalén era un elemento fundamental en la demarcación de la identidad nacional. Porque para la concepción de sociedad que el autor ha imaginado, Jerusalén es simbólicamente esencial.

\section{Restauración genealógica en Nehemías 3.1-32}

Para Smith, una etnia está simbólicamente instaurada sobre la base de una legitimación familiar o de parentesco, de tal modo que la constitución de una nacionalidad étnica requiere de un movimiento de restauración genealógica para establecer la identidad en la conformación de dinastías o aristocracias como símbolos fundantes, o sea, la configuración de las élites implica la configuración simbólica del pueblo. También en "tratar de revivir el ethos antiguo de una política decadente ${ }^{19 \prime \prime}$ (SMITH, 1988: p. 52), es decir que la construcción de una nacionalidad está asimismo asociada con la reinstauración de gobiernos monárquicos o de institucionalidades gubernamentales anteriores, las que igualmente fueron formadas por un orden genealógico.

Nehemías 3.1-32 no pretende presentar un rol de trabajadores en la reedificación de los muros de Jerusalén, es más, explícitamente el autor no nombra a los trabajadores; sino una lista de los jefes de las familias de quienes participaron en los trabajos, es decir que existe una visible intención de validar a las élites como fundamento en la reconstrucción simbólica de la territorialidad étnica, por ende, en la construcción del orden social de su nación imaginada.

Propongo tres ideas que sustentan mi argumento:

Uno, la inclusión de una lista de reconstructores de los muros de Jerusalén que registra nombres, procedencias y relaciones de parentesco fue un recurso historiográfico para legitimar la nacionalidad étnica judía.

Se ha postulado que Nehemías 3.1-2 podría ser un "documento de archivo o unas notas para la organización” (SCHÖKEL, 1976: p. 257), cuyo énfasis es la distribución de 42 grupos para llevar a cabo la tarea ar-

\footnotetext{
18 "The decision to place the returnees in sites primarily within Benjamin has been motivated by concerns other than an accurate reporting of events. One underlying motivation may have been a desire to claim that those in Yehud who had returned from Babylonia were true heirs to the name Israel and represented this entity in its transformation into a religious community instead of a kingdom".

19 "to revive the ancient ethos of a decaying polity".
} 
quitectónica, y que está narrado con un visible afán por el repartimiento minucioso de la labor; sin embargo, luego de revisar el texto podemos darnos cuenta que más bien carece de exactitud, por eso en la actualidad "se reconoce ampliamente que la lista de reparaciones y trabajadores está incompleta ${ }^{20 "}$ (EDELMAN, 2005: p. 210; traducción nuestra), y más bien parece que la última compilación sería el resultado de que un "escriba haya editado a la ligera algunas otras partes de Esdras-Nehemías ${ }^{21}[. ..] \mathrm{La}$ historia compositiva del libro de Esdras-Nehemías es un tema complejo, difícil y extraordinariamente fascinante ${ }^{22 \prime \prime}$ (KNOPPERS, 2005: p. 73; traducción nuestra).

Por el contrario, debido a la cosmovisión del sacerdocio del segundo templo, y a su tarea política, la que venimos explorando, se puede notar que la importancia del texto y su inclusión en el libro, no radica en la exactitud de los nombres de los constructores, de sus lugares y de la consanguinidad de sus relaciones; sino en el valor que tiene una genealogía para sostener la homogeneización del pasado, que dio fundamento a la centralidad simbólica de Jerusalén. Las genealogías fueron instrumentos políticos para legitimar la identidad de un pueblo en el montaje de relaciones de parentesco, porque logran garantizar el vínculo étnico de la población.

JL Ska analiza la historiografía de Israel y concluye que:

Por una parte, estos relatos pretenden definir al pueblo a partir de las «genealogías». En la mentalidad popular que se refleja en este tipo de relatos, ésta era una manera sencilla y eficaz de afirmar la identidad del pueblo: los israelitas se distinguen de los pueblos vecinos - como los amonitas, los moabitas, los filisteos, los ismaelitas, los arameos y los edomitas- porque tienen antepasados diferentes. Por otra parte, esta «genealogía» fundamenta algunos «derechos fundamentales» de los pueblos, como el derecho a la tierra. (SKA, p. 24, versión en Word)

Acerca del trabajo onomástico, los textos de Nehemías 3.1-32 "presentan nombres que aparecen en gran parte, aunque desordenados, en la gran lista duplicada de Esd 2 y Neh 7" (CORTESE, 2005; p.803). La repetición de esta lista nos manifiesta su valía etiológica en el proyecto de instauración de las élites judías en Yehud. Nehemías 7 quiere transmitir la noción de que la genealogía es vital para la refundación de Israel porque explicita la llegada de los exiliados para repoblar Judá; mientras que Esdras 2 más bien intenta resaltar la refundación del templo y su institucionalidad. Por tanto la relación entre los nombres de Nehemías 3 y 7 guardaría la intención de darle también al relato de Nehemías 3.1-32 un

\footnotetext{
20 "it is widely acknowledged that the list of repairs and laborers is incomplete".

21 "this scribe lightly edited certain other parts of Ezra-Nehemiah".

22 "he compositional history of the book of Ezra-Nehemiah is a complex, difficult, and extraordinarily fascinating issue".
} 
valor etiológico, sobre todo porque se trata de la reconstrucción de la emblemática Jerusalén.

Estos nombres identifican a personajes que no aparecen solos, sino en redes relacionales que pueden ser complejas de entenderlas en nuestra lógica contemporánea. Por ejemplo, en el versículo 17, cuando se nombra a algunos levitas, Rejún es relacionado con Baní, como hijo, cuestión común en el relato; pero a su lado aparece Jerabías sin ser hijo de algún otro personaje. En los versos 4 y 21, Meremot aparece con una doble mención paterna, como hijo de Urías, hijo de Hacós, a diferencia del resto de personajes a quienes sólo se adjudica una mención paterna.

Consideremos que en sociedades premodernas, las relaciones de parentesco son vitales para la unidad étnica del pueblo, lo que aporta a la edificación de la identidad nacional. En la lista que estamos estudiando, hasta el versículo 6 se hace referencia a los constructores como hijos de otro personaje, pero en el verso 7 los trabajadores ya serán hijos de un pueblo como Gabaón, Meronot, Mispá. Existe la pretensión de que los lectores judíos sepan que tienen orígenes comunes que los hace ser pueblo, y esa es la función del reconocimiento del parentesco, que conceptualmente está alejado de la consanguinidad, forma de establecer vínculo familiar en el pensamiento occidental.

Estas redes de parentesco normalizan la etnicidad como sostén de la nacionalidad, lo que es tajantemente notificado en la expresión de Esdras 2.59b: "los cuales no pudieron probar que su familia y su estirpe eran de origen israelita".

Las genealogías fueron una forma de apropiarse del pasado a través del trazo de redes de parentesco que no pretendían reportar fidedignamente acontecimientos o personajes; sino construir relaciones únicas entre el presente del pueblo y lo imaginado del pasado, para así unificar la conciencia de sus orígenes y, por consiguiente, de su identidad nacional, porque "lo ahistórico y lo histórico son en igual medida necesarios para la salud de un individuo, de un pueblo o de una cultura" (NIETZSCHE, 2009: p. 331).

Dos, la genealogía de Nehemías 3.1-32 tiene una notoria predilección de aportar a la cimentación de la clase sacerdotal como núcleo de la élite, afianzando así los ideales de nación de los sadoquitas.

La lista comienza nombrando al sumo sacerdote Eliasib, contemporáneo de Nehemías, y más adelante, en los versículos 20 y 21, aparece nuevamente debido a los trabajos que se realizan en su casa. Las familias de los sacerdotes se encargaron de gran parte de reconstrucción de los muros, "la actividad de los grupos levíticos se inicia en el v. 17 y la de los sacerdotes en el v. 22" (CORTESE, 2005: p. 803), incluso construyendo sus propias casas.

Según Nehemías 12.10, el sumo sacerdote Eliasib fue abuelo de Yehojanán, contemporáneo con Esdras, y “desempeñó el mismo cargo en 
tiempo de Esdras (Esd 10,6). Los papiros de Elefantina vienen a confirmar que Yehojanán fue sumo sacerdote en la última década del siglo V a.C." (LEAL et. al, 1969: p.42), lo que ratifica el estatus de este sacerdote durante la misión de Nehemías. No resulta extraño, entonces, que aparezca inaugurando los trabajos de reconstrucción de Jerusalén, porque quienes editaron el texto final de Nehemías fueron sacerdotes, con evidentes inclinaciones de fundar una nación teocrática (GALLAZZI, 1996).

Smith recalca que el movimiento genealógico pretende que lo étnico esté fundado en la conexión con el pasado a través de la constitución de linajes y dinastías. Los sacerdotes tuvieron la intención de asentarse como élite, por tanto les era necesario aparecer en los documentos genealógicos para reclamar su pertenencia a un linaje y cimentar una plataforma desde donde, al fin, pudieron determinar quién era sujeto y quién no alcanzaba esta normalización.

Tres, una intención notable del autor es advertir la categoría de ciudadanía y la responsabilidad en el trabajo que tuvieron los jefes de familias en la reedificación de la ciudad. R. North (1971) hace referencia a la observación de H. Kaupel (Bib 21 (1940), 40), para quien el concepto "los 'ejecutores de la obra' significa 'la administración de la obra' más que los obreros” (p. 261). Es decir que discursivamente se está configurando la élite de Judá en la pretensión que el historiador tiene por ubicar a los jefes de familias en un acontecimiento simbólicamente valioso del pasado, la reedificación de los muros de la mítica Jerusalén, documentando no sólo su participación, sino su representatividad.

Sacerdotes (v. 1, 20, 28), líderes de los gremios de orfebres y perfumeros (v. 8, 31, 32), jefes de distrito o de la mitad de un distrito (v. 9, 12, 14, $15,16,17,18)$, levitas (v. 17), comerciantes (v. 31, 32) son las distinciones de los que dirigieron los tramos de la reconstrucción de los muros y puertas.

La pretensión del autor, sobre todo del editor, fue resaltar las posiciones de privilegio, para así contribuir a las marcas de la subjetividad que caracterizan a la etnia, en este caso, judía.

\section{Renovación cultural y pureza étnica en Nehemías 3.33-4.17}

Mientras que en el capítulo 3 se ha planteado la construcción identitaria desde la apropiación del espacio y configuración de una territorialidad étnica, además del afianzamiento de las élites como lugar para el despliegue del ideal nacional, a partir del uso de las genealogías; en la sección del 3.33 al 4.17, se retoma en la narrativa las memorias de Nehemías para que, desde una oposición binaria que contrapone lo propio con lo ajeno, se coadyuve a la configuración de la identidad nacional. Lo que planteo es que en esta unidad literaria se sustenta la noción de que el judío construye más su patriotismo, por ende se apropia más de lo que ha enarbolado como cultura propia, en la diferencia nacional/extranjero, que se fortalece 
en la asociación conceptual de que lo extranjero es enemigo y lo nacional, es hermano, sustentado en el valor simbólico del parentesco.

Para H. Williamson (1999), la pretensión del autor de las memorias de Nehemías, sobre todo en la sección de 4.1-14, es recurrir a ciertos aspectos de la Ley, especialmente deuteronómica, para proponer una reedición de la guerra santa. Recurre a Kellerman quien ha distinguido

las siguientes conexiones: el ejército enemigo se junta contra Jerusalén; la gente ora antes de armarse; los recursos humanos para la defensa son escasos; las fuerzas son una milicia de conscriptos en lugar de un ejército permanente; el líder proclama la participación de Dios en la batalla y llama a la fe y la audacia; el enemigo está desanimado; y la explosión de la trompeta es la señal para la batalla23 (WILLIAMSON, 1999: p. 278-279; traducción nuestra).

Este acceso histórico al pasado es totalmente afianzador de la cultura que se está produciendo y asumiendo como propia en el pueblo. Según Smith, la renovación cultural como aspecto fundamental del nacionalismo étnico, no sólo tiene que ver con las élites y su fuerza normalizadora de la identidad; más bien parte y llega a todo el pueblo. La narrativa de Nehemías 4.1-14 recurre a la ley deuteronómica que no era una producción original de las élites posexílicas; sino que había sido diseminada y apropiada por un pensamiento más popular, es decir que el relato está arraigando la idea de que la territorialidad étnica de Jerusalén más que un asunto del sacerdocio o de los grupos dominantes, es una insignia de todo el pueblo.

Smith (1988) plantea que los movimientos culturales que sustentan la nacionalidad étnica "buscan un resurgimiento de la cultura de toda la comunidad. También van más allá de la liberación territorial, que a veces es un medio y un preludio para la renovación de una herencia étnica ante amenazas externas ${ }^{24 \prime}$ (p. 53, traducción nuestra). Lo que justamente acontece con la concepción narrativa del relato que se conecta con el final del capítulo 2. Las memorias de Nehemías explican que la reconstrucción de Jerusalén es un proyecto del pueblo que está amenazado, desde todos los flancos, por aquellos que no solamente no pertenecen pueblo; sino que se han constituido como enemigos. El texto en 4.7 narra que "con estos filisteos (Asdod) a Occidente, el círculo que cerca Israel queda cerrado: Samaría al norte, Ammón al este y los árabes al sur (2.9-19). Israel queda totalmente rodeado de enemigos" (NORTH, 1971: p. 263).

\footnotetext{
23 "the following series of connections: the enemy band together against Jerusalem; the people pray before arming themselves; the human re- sources for defence are slender; the forces are a conscript militia rather than a standing army; the leader proclaims God's involvement in the battle and calls for faith and fearlessness; the enemy is discouraged; and the trumpet blast is the signal for battle".

24 "seek a revival of the culture of the whole commmunity. They also go beyond territorial liberation, which sometimes as a means and a prelude to the renewal of an ethnic heritage in the face of external threats".
} 
Con Samaria existe una riña particular, no escondida por Esdras-Nehemías. Sanbalat, que representa a una dinastía samaritana, es el enemigo principal de la reconstrucción de Jerusalén, cuestión que necesita ser ratificada en la conciencia del pueblo, más aún en los inicios de la época helénica, porque han recrudecido las desavenencias político-religiosas, en el seno de la institucionalidad sacerdotal.

Las tensiones entre Samaria y Jerusalén que caracterizan la época persa continúan en la época helenística. Parece que en los inicios de esta época se construye un templo en la cima de Garizin. Hay muchos indicios que su sacerdocio procede de Jerusalén, que, debido a una serie de conflictos internos, abandona aquel templo. Esto indica claramente que el culto en el Garizin se ofrece también al Dios de Israel (KESSLER, 2013: p. 276)

El relato contiene elementos particulares, por un lado la afrenta primera de Sanbalat es la emisión de sátiras con una intención peyorativa, más que una perpetración militar violenta, pero trastoca el honor de dos representaciones socioculturales que en sí mismas tienen una carga de significado que implica poder: el ejército y las murallas de Jerusalén. "Ejército (hayil) significa 'vigor', económico o militar; es un término sociológico tan difícil de precisar como 'am hâa-âres (Esd 4,4;9,2) del que es antítesis" (NORTH, p. 263). El relator busca sensibilizar a los lectores narrando de manera muy sentida el menoscabo que produjo la burla de Sanbalat.

La siguiente afrenta ya se trata de la amenaza de una incursión militarizada que tiene como fin la destrucción de las murallas, como hemos señalado en el capítulo 3 se ha procurado erigir a los muros de Jerusalén como una insignia etno-simbólica de la cultura judía, así que amenazar con destruirla es vilipendiar la misma cultura judía, por lo que la única forma de calificar a quienes infaman es llamándoles enemigos.

Lo tercero es la arenga de Nehemías en el verso 4.8b: "pelead por vuestros hermanos, por vuestros hijos y por vuestras hijas, por vuestras mujeres y por vuestras casas", la discrepancia se ha convertido en un problema político al que Nehemías responde con una convocatoria al pueblo para afianzar el parentesco a través de sentencias categóricas que discursivamente implantan la noción de hermandad. La tarea de la reconstrucción de Jerusalén no es monopolio de las élites, ni algo en beneficio de ellas, es por y para todos los que comparten la misma nacionalidad étnica, los de Judá.

En la perícopa se va consolidando el concepto de hermandad hasta el verso final que certifica la relación de Nehemías con el pueblo: "Yo mismo, mis familiares, mis gentes...", en la versión Reina Valera se traduce: "Y ni yo ni mis hermanos, ni mis jóvenes...", pero este fortalecimiento del concepto va de la mano con la acentuación de un concepto opuesto: enemigos. Cortese (2005) comenta que desde el capítulo 2 la narrativa ha 
tratado la enemistad de Sanbalat y sus cómplices "en movimiento in crescendo" (p. 804) hasta llegar al versículo 3.38 "mediante una convención estilística, que prepara el punto máximo de hostilidad" (p. 804), para así llegar al capítulo 4 donde la enemistad llega a su punto más culmen, para luego comenzar con la narración que encumbra el máximo sentido de la hermandad.

La oposición hermandad/enemistad, asociada con nacional/extranjero, distingue plenamente la identidad del sujeto que pertenece al pueblo o nación, porque simbólicamente ya no admite dudas respecto a quien es del pueblo y quien no, más si la hermandad significa compartir símbolos culturales que, gracias al alcance de la identidad nacional, ahora pertenecen al pueblo y no solamente a las élites, e incluso las élites representan al pueblo. Es decir, se ha logrado consolidar la etnicidad.

\section{A manera de conclusión}

El ecuatoriano sabe que el 24 de mayo es una fecha para sentirse más ecuatoriano, porque simbólicamente representa un origen de la patria. El ecuatoriano no apela ni se pregunta por qué en la imaginación colectiva el acontecimiento a recordar es la Batalla de Pichincha, él sabe que es la que permitió la anhelada expulsión de los españoles y la consecución de la tierra que entendió suya. Nunca demandará a las élites político-militares por borrar de la memoria colectiva cualquier otro recuerdo del 24 de mayo, es más considerará como héroe a José A. Sucre y a todo aquel que dirigió la empresa libertaria. Y al fin, se sabrá más ecuatoriano si guarda en su memoria y también en su conciencia, esta fecha insigne.

Del mismo modo, al judío le hacía saberse más judío si recordaba que la vieja Jerusalén había sido reconstruida, por un animado y esforzado grupo de héroes que se enfrentaron a los más viles enemigos, máxime por que la mano de Dios estuvo de parte de este enflaquecido ejército de constructores, que se hicieron fuertes gracias al liderazgo de Nehemías y al beneplácito de su poderosa divinidad, que, sin duda estuvo presente, porque fueron los sacerdotes, representantes de lo divino en la tierra, quienes protagonizaron la recuperación de la territorialidad de su mítica Jerusalén.

La Historia se había apropiado de su pasado, convirtiéndolo en único e inapelable, al fin y al cabo, era y, al parecer aún es, una excelente vía para asentar lo étnico como soporte de aquello que le ha dado la esperanza de creer que algún día llegaría su libertad: la identidad nacional.

Por eso, Nehemías 3 y 4 realmente forman parte de un compendio histórico, al que la famosa búsqueda crítica de la historicidad científica de la modernidad no puede cuestionar por sus inexactitudes o por su incongruencia, porque entre otras cosas, los relatos de Nehemías 3 y 4 también son construcciones históricas de la institucionalidad gobernante, para que 
a través de sus datos se homogenice un pasado a favor de la anhelada identidad nacional.

Entonces, tomo las palabras de P. Ricoeur (2003, p. 23) para afirmar que la Historia puede adueñarse del pasado y construir identidades a través de esta apropiación, lo ha hecho y lo hará, pero aún debe existir la esperanza de que el pasado no ha sido plenamente atrapado.

Y sin embargo... $Y$, sin embargo, no tenemos nada mejor que la memoria para garantizar que algo ocurrió antes de que nos formásemos el recuerdo de ello. La propia historiografía - digámoslo ya - no logrará modificar la convicción, continuamente zaherida y continuamente reafirmada, de que el referente último de la memoria sigue siendo el pasado, cualquiera que pueda ser la significación de la 'paseidad' del pasado. 
ABADIE, P. El libro de Esdras y Nehemías: Cuadernos Bíblicos 95. Navarra: Editorial Verbo Divino, 1998.

AGUILERA, M. J. Las monedas Yehud. En: Revista Numismática OMNI, Número 12, p. 14-53, Jun / 2018.

ALSINA, M. y MEDINA, P. Posmodernidad y crisis de identidad 2006. "“".

En: IC Revista Científica de Información y Comunicación, Sevilla.

Número 3, (2006),. P. 125-146. Disponible en: http://institucional. us.es/revistas/comunicacion/3/art8.pdf

ALTHUSSER, L. La ideología y aparatos ideológicos del Estado. Medellín: Editorial la Oveja Negra, 1976.

ANDIÑACH, P. R. Introducción hermenéutica al Antiguo Testamento. Navarra: Editorial Verbo Divino, 2012.

BAUMAN, Z. La cultura en el mundo de la modernidad líquida. México: Fondo de Cultura Económica, 2013.

CORTESE, E. Esdras y Nehemías. En: LEVORATTI, A. J. Comentario bíblico latinoamericano: Antiguo Testamento Vol I, Pentateuco y textos narrativos. Navarra: Editorial Verbo Divino, 2005, p. 789-819.

CROATTO, J. S. Las culturas del antiguo Próximo Oriente: desde los orígenes hasta la conquista de Jerusalén 63 a. C. Buenos Aires: ISEDET, EDUCAB, 1994.

EDELMAN, D. The origins of the 'Second' Temple: Persian imperial policy and the rebuilding of Jerusalem. Londres: Equinox Publishing Ltd. 2005.

ESTRADA, A. Identidad: Zygmunt Bauman. En: Comunicación Revista internacional de comunicación audiovisual, publicidad y estudios culturales, Sevilla. 2006 Número 4, p. 297-301, 2005.

FINKELSTEIN, I. y SILBERMAN, N. A. La Biblia desenterrada: una nueva visión arqueológica del antiguo Israel y de sus textos sagrados. $3^{\circ}$ edición. Madrid: Siglo XXI España, 2011.

FOUCAULT, M. Nietzche, la genealogía y la Historia. En Microfísica del Poder. Madrid: Ediciones La Piqueta, 1980, pp. 7-29.

GALLAZZI, S. La sociedad perfecta según los sadocitas: el libro de los Números. En: RIBLA Revista de Interpretación Bíblica Latinoamericana, Quito, Número 23, p. 153-167, 1996.

GAYO, M. G. El origen de las naciones y los nacionalismos en la obra de Anthony D. Smith y el papel de la política, una perspectiva diacrónica. En: Revista de Estudios Políticos Nueva Época, Número 114, p. 251-276, oct-dic / 2001.

- GRAMSCI, A. Política y Sociedad. Barcelona: Ediciones Península, 1977. 
HOGLUND, K. G. Achaemenid Imperial Administration in Syria-Palestine and the Missions of Ezra and Nehemiah. Atlanta: Scholars Press, 1992

HOYOS DE LOS RÍOS, O. L. Identidad nacional: algunas consideraciones de los aspectos implicados en su construcción psicológica. En: Psicología desde el Caribe, Barranquilla, núm. 5, enero-julio, 2000, pp. 56-95, may / 2000.

JAPHET, S. I \& II Chronicles: a commentary. Louisville, Londres: Westminster John Knox Press, 1993.

KESSLER, R. Historia social del antiguo Israel. Salamanca: Ediciones Sígueme, 2013.

KNOPPERS, G. N. I Chronicles 10-29: the Anchor Yale Bible Commentaries. New Haven: Yale University Press, 2004.

KNOPPERS, G. N. Of rewritten Bibles, Archaeology, Peace, Kings, and Chronicles. En: The Journal of Hebrew Scriptures, New studies in Chronicles: a discussion of two recently-published commentaries, vol. 5, article 20, p. 69-93, Nov / 20 / 2005.

LEAL, J. Et al. Antiguo Testamento III: La Sagrada Escritura, texto y comentario. Madrid: Biblioteca de Autores Cristianos, 1969.

MENCHÉN, J. Historia cronística: Crónicas, Esdras y Nehemías, texto y comentario. Madrid, Salamanca, Navarra: Atenas, PPC, Sígueme, Verbo Divino, 1995.

NIETZSCHE, F. Sobre la utilidad y el perjuicio de la Historia para la vida. En: CANO, G. Nietzsche. Madrid: Editorial Gredos, 2009, p. 321404.

NORTH, R. El cronista: 1-2 Crónicas, Esdras, Nehemías. En: BROWN, R. Comentario bíblico "San Jerónimo". Madrid: Ediciones Cristiandad, 1971, p. 173-272.

NOTH, M. Historia de Israel. Barcelona: Ediciones Garriga S. A., 1966.

PAGÁN, S. Esdras, Nehemías y Ester: Comentario bíblico hispanoamericano. Miami: Editorial Caribe INC, 1992.

RAFFESTIN, C. Por una geografía del poder. Zamora de Hidalgo: El Colegio de Michoacán, 2011.

RICOEUR, P. La memoria, la historia, el olvido. Madrid: Editorial Trotta S. A., 2003.

SCHÖKEL, L. A. Crónicas, Esdras, Nehemías. Madrid: Ediciones Cristiandad, 1976.

SKA, J-L. Los enigmas del pasado (versión en Word). Quito: Verbo Divino, 2003.

SMITH, A. D. Ethno-symbolism and nationalism: a cultural approach. Londres y Nueva York: Routledge, Taylor \& Francis Group, 2009.

SMITH, A. D. The ethnic origins of nations. Oxford: Blackwell Publishing Ltd., 1988. 
STEINS, G. Os livros de Esdras e Neemias. En: ZENGER, E. Et al. Introdução ao Antigo Testamento. Sao Paulo: Ediçoes Loyola Jesuitas, 2003, p. 222-232.

WILLIAMSON, H. G. M. 1 \& 2 Chronicles: The New Century Commentary Bible. Grand Rapids: W.B. Eerdmans Publishing Company, 1982.

WILLIAMSON, H. G. M. The belief system of the book of Nehemiah. En: BECKING B. y KORPEL, M. C. A. The crisis of Israelite religion: transformation of religious tradition in Exilic \& Post-exilic times. Leiden, Boston, Köln: BRILL, 1999, p. 276-287. 